\title{
On the value of $c$ : can low affinity systems be studied by isothermal titration calorimetry?
}

\author{
W. Bruce Turnbull* and Antonio H. Daranas*
}

\section{SUPPORTING INFORMATION}

\section{Derivation of Equation 7}

page $S 2$

Fig. S1. Simulated titrations and curve fitting for: $K_{\mathrm{a}}=10^{3} ; \square H^{\mathrm{o}}=-2 \mathrm{kcal} \mathrm{mol}^{-1} ; c=0.001-10$

page $S 3$

Fig. S2. Simulated titrations and curve fitting for: $K_{\mathrm{a}}=10^{3} ; \square H^{\mathrm{o}}=-5 \mathrm{kcal} \mathrm{mol}^{-1} ; c=0.001-10$

page $S 3$

Fig. S3. Simulated titrations and curve fitting for: $K_{\mathrm{a}}=10^{3} ; \square H^{\mathrm{o}}=-10 \mathrm{kcal} \mathrm{mol}^{-1} ; c=0.001-10$

page $S 4$

Fig. S4. Simulated titrations and curve fitting for: $K_{\mathrm{a}}=10^{3} ; \square H^{\mathrm{o}}=-15 \mathrm{kcal} \mathrm{mol}^{-1} ; c=0.001-10$ page $S 4$

Fig. S5. Simulated titrations and curve fitting for: $K_{\mathrm{a}}=10^{3} ; \square H^{\mathrm{o}}=-20 \mathrm{kcal} \mathrm{mol}^{-1} ; c=0.001-10$ page 55

Fig. S6. Summary of errors in $\square G^{\text {o }}$

page S6

Fig. S7. Summary of errors in $\square H^{\circ}$

page S6 


\section{Derivation of Equation 7}

For the equilibrium:

$\mathrm{X}+\mathrm{M} \mathrm{XM}$

The dissociation constant, $K_{\mathrm{d}}$ is defined as:

$K_{\mathrm{d}}=\frac{[\mathrm{X}][\mathrm{M}]}{[\mathrm{MX}]}$

where $[\mathrm{X}],[\mathrm{M}]$ and $[\mathrm{MX}]$ are the concentrations of the free ligand, free receptor and complex, respectively. The total ligand and total receptor concentrations $\left([\mathrm{X}]_{t}\right.$ and $\left.[\mathrm{M}]_{t}\right)$ can be defined as:

$$
\begin{aligned}
{[\mathrm{X}]_{t} } & =[\mathrm{X}]+[\mathrm{MX}] \\
{[\mathrm{M}]_{t} } & =[\mathrm{M}]+[\mathrm{MX}]
\end{aligned}
$$

thus,

$$
K_{\mathrm{d}}=\frac{[\mathrm{X}]\left([\mathrm{M}]_{t} \square[\mathrm{X}]_{t}+[\mathrm{X}]\right)}{[\mathrm{X}]_{t} \square[\mathrm{X}]}
$$

Rearranging this equation gives:

$$
[\mathrm{X}]^{2}+\left([\mathrm{M}]_{t} \square[\mathrm{X}]_{t}+K_{\mathrm{d}}\right)[\mathrm{X}] \square K_{\mathrm{d}}[\mathrm{X}]_{t}=0
$$

the only possible root of which is given by:

$$
[\mathrm{X}]=\frac{[\mathrm{X}]_{t} \square[\mathrm{M}]_{t} \square K_{d}+\sqrt{\left([\mathrm{M}]_{t} \square[\mathrm{X}]_{t}+K_{d}\right)^{2}+4[\mathrm{X}]_{t} K_{d}}}{2}
$$

but, as $[\mathrm{MX}]=[\mathrm{X}]_{t} \square[\mathrm{X}]$, then,

$$
[\mathrm{MX}]=[\mathrm{X}]_{t} \square \frac{[\mathrm{X}]_{t} \square[\mathrm{M}]_{t} \square K_{d}+\sqrt{\left([\mathrm{M}]_{t} \square[\mathrm{X}]_{t}+K_{d}\right)^{2}+4[\mathrm{X}]_{t} K_{d}}}{2}
$$

Rearrangement of the expression under the square root sign provides another common variant of this equation:

$$
[\mathrm{MX}]=[\mathrm{X}]_{t} \square \frac{[\mathrm{X}]_{t} \square[\mathrm{M}]_{t} \square K_{d}+\sqrt{\left([\mathrm{M}]_{t}+[\mathrm{X}]_{t}+K_{d}\right)^{2} \square 4[\mathrm{X}]_{t}[\mathrm{M}]_{t}}}{2}
$$



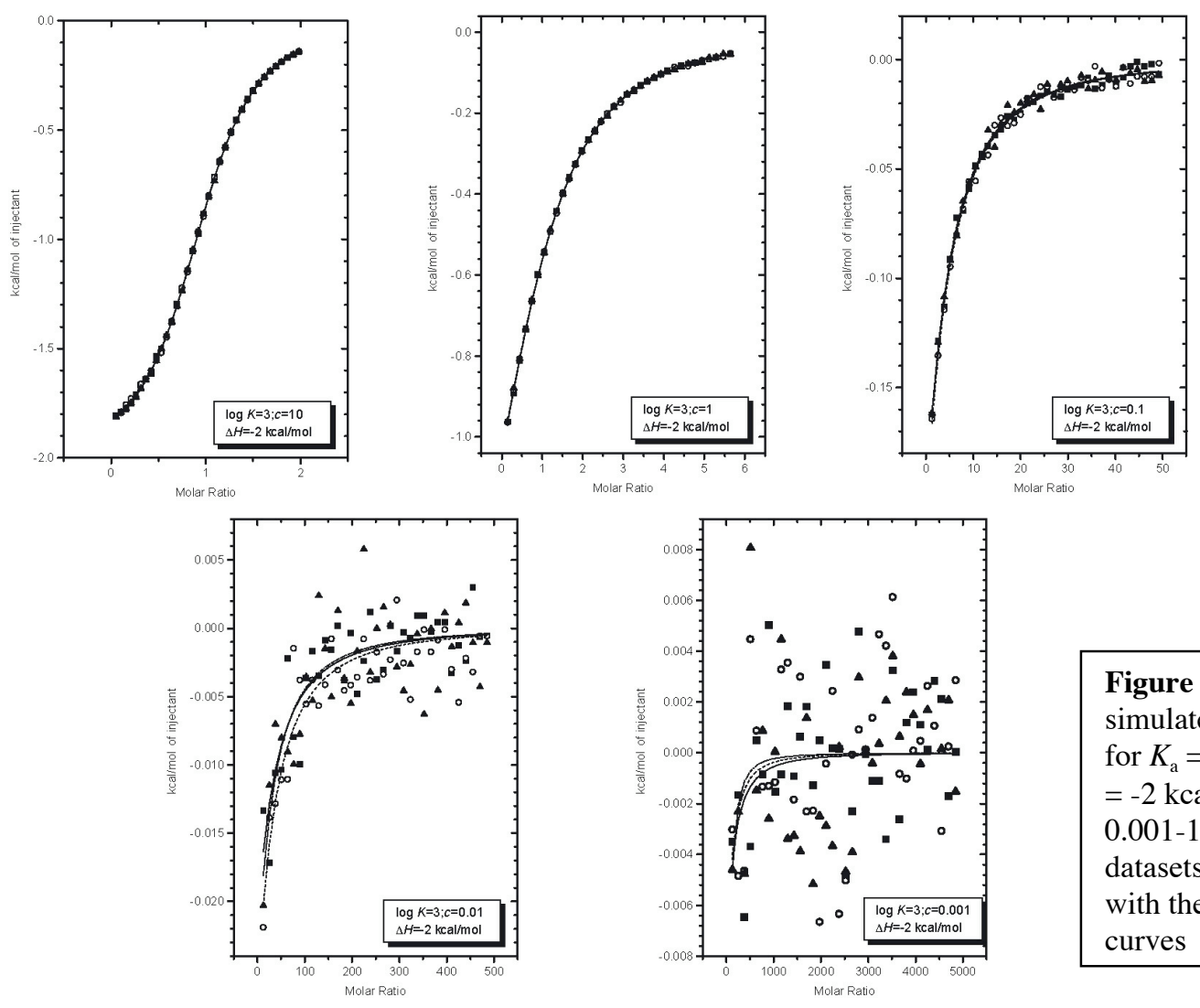

Figure S1. Example simulated titration data for $K_{\mathrm{a}}=1000 \mathrm{M}^{-1} ; \square H^{\mathrm{o}}$ $=-2 \mathrm{kcal} \mathrm{mol}^{-1} ; c=$ 0.001-10. Three datasets are overlayed with their best fitting curves
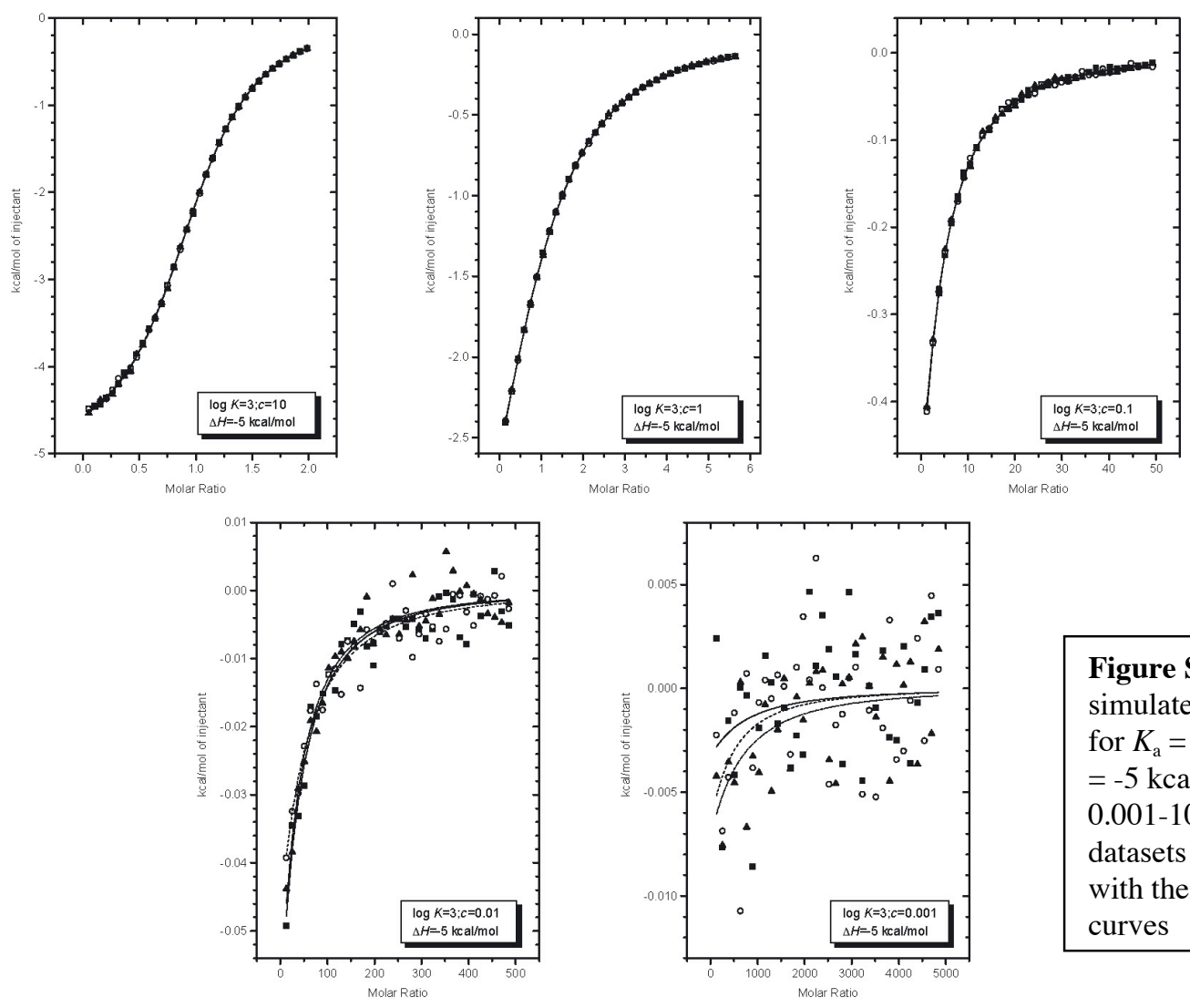

Figure S2. Example simulated titration data for $K_{\mathrm{a}}=1000 \mathrm{M}^{-1} ; \square H^{\circ}$ $=-5 \mathrm{kcal} \mathrm{mol}^{-1} ; c=$ 0.001-10. Three datasets are overlayed with their best fitting curves 

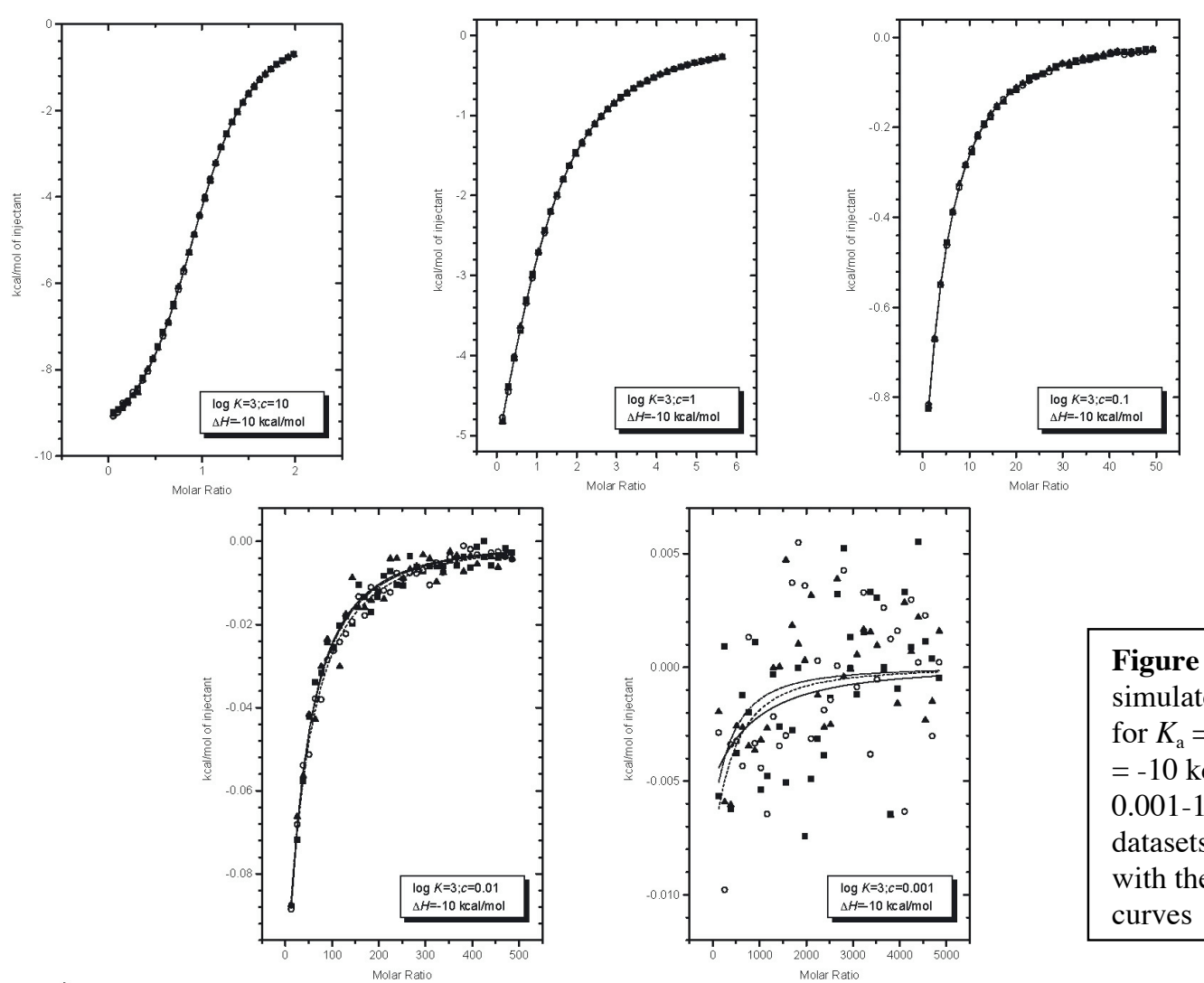

Figure S3. Example simulated titration data for $K_{\mathrm{a}}=1000 \mathrm{M}^{-1} ; \square H^{\circ}$ $=-10 \mathrm{kcal} \mathrm{mol}^{-1} ; c=$ 0.001-10. Three datasets are overlayed with their best fitting curves

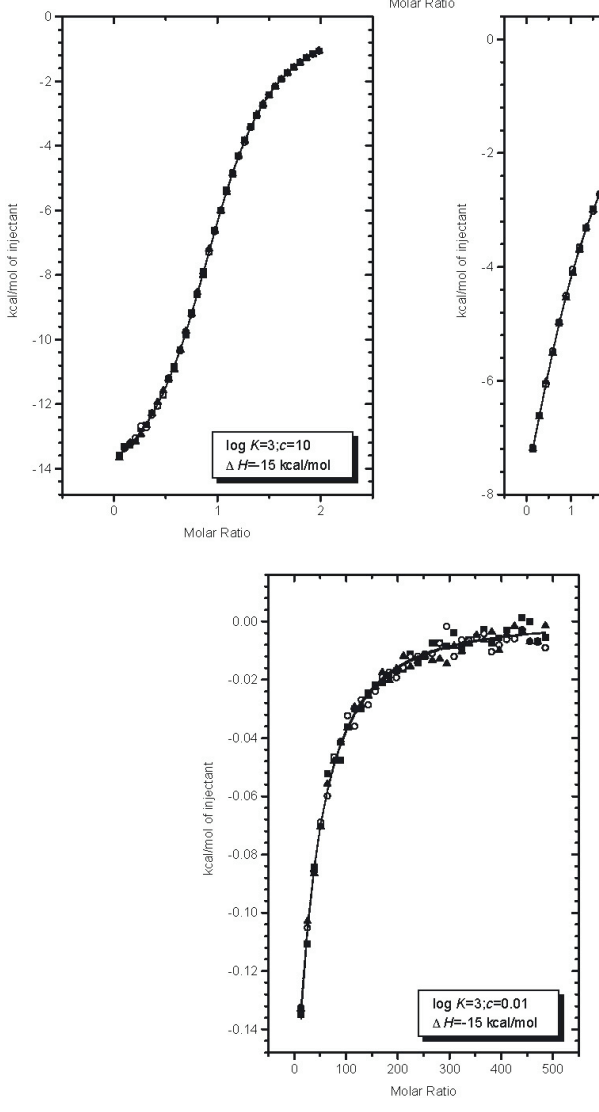

Moler Ratio
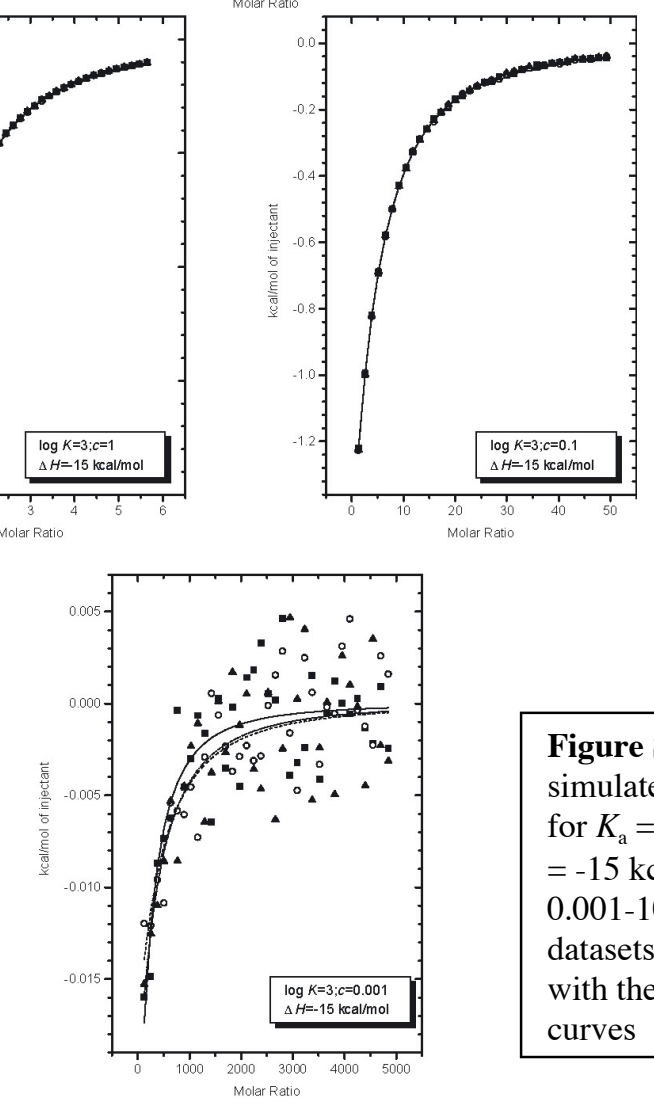

Figure S4. Example simulated titration data for $K_{\mathrm{a}}=1000 \mathrm{M}^{-1} ; \square H^{\circ}$ $=-15 \mathrm{kcal} \mathrm{mol}^{-1} ; c=$ 0.001-10. Three datasets are overlayed with their best fitting curves 

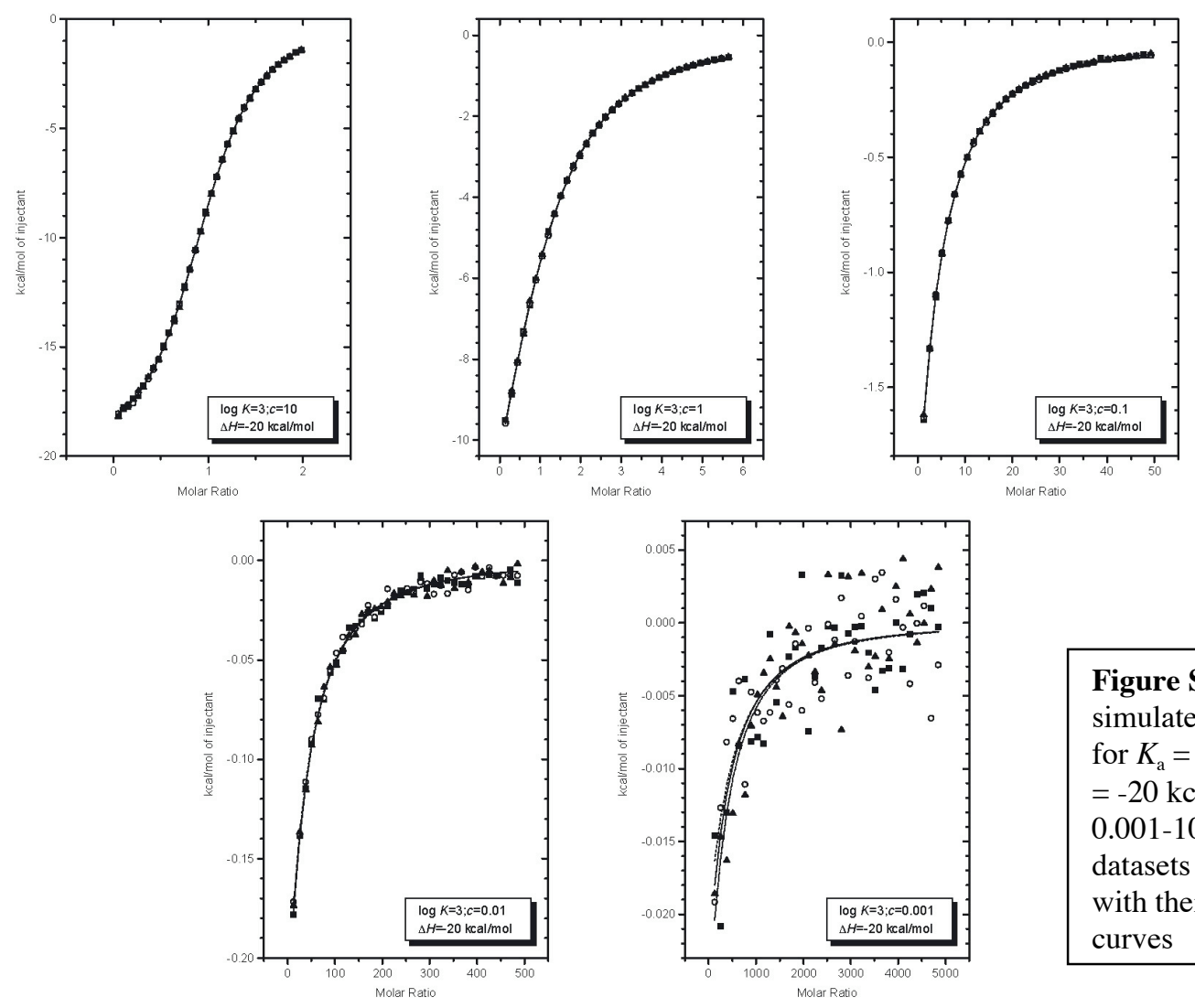

Figure S5. Example simulated titration data for $K_{\mathrm{a}}=1000 \mathrm{M}^{-1} ; \square H^{\circ}$ $=-20 \mathrm{kcal} \mathrm{mol}^{-1} ; c=$ 0.001-10. Three datasets are overlayed with their best fitting curves 

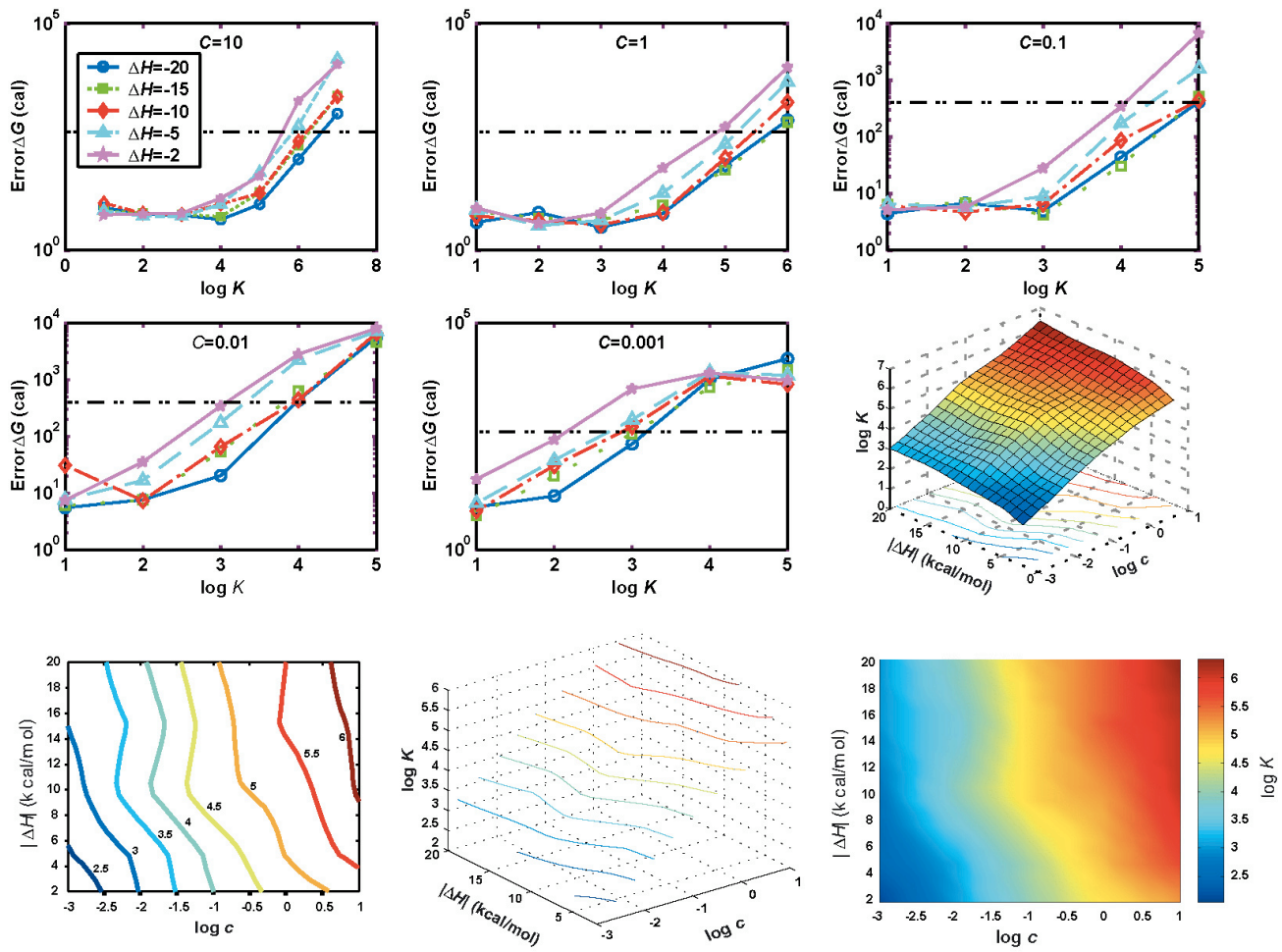

Figure S6. $\log \left(K_{\mathrm{a}}\right) v s$. mean errors (+ two standard deviations) in $\square G^{\mathrm{o}}$ for all values of $c$ and $\square H^{\mathrm{o}}$ used in the simulations. The dashed line represents the threshold error limit of $0.4 \mathrm{kcal} \mathrm{mol}^{-1}$ used for constructing the surface and contour plots.
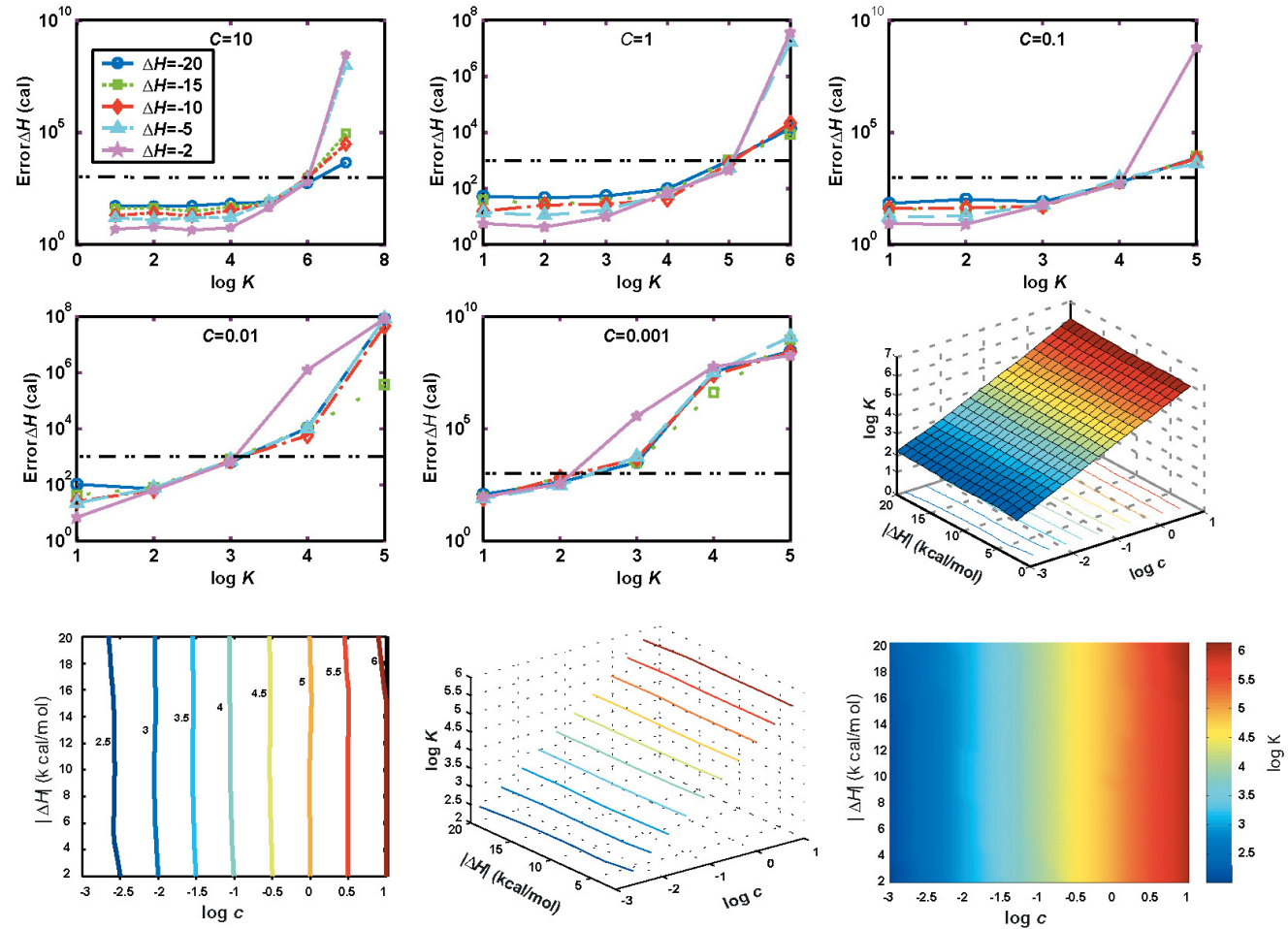

Figure S7. $\log \left(K_{\mathrm{a}}\right)$ vs. mean errors (+ two standard deviations) in $\square H^{\circ}$ for all values of $c$ and $\square H^{\circ}$ used in the simulations. The dashed line represents the threshold error limit of $1.0 \mathrm{kcal} \mathrm{mol}^{-1}$ used for constructing the surface and contour plots. 